Abstract

\title{
Label-Free DNA Detection with Capacitive Field-Effect Devices-Challenges and Opportunities ${ }^{+}$
}

\author{
Michael J. Schöning 1,2,*, Thomas S. Bronder ${ }^{1}$, Chunsheng Wu ${ }^{1}$, Sabrina Scheja ${ }^{1}$, Max Jessing ${ }^{1}$, \\ Christoph Metzger-Boddien ${ }^{3}$, Michael Keusgen ${ }^{4}$ and Arshak Poghossian ${ }^{1,2}$ \\ 1 Institute of Nano- and Biotechnologies (INB), FH Aachen University of Applied Sciences, 52428 Jülich, \\ Heinrich-Mußmann-Str. 1, Germany \\ 2 Institute of Complex Systems (ICG-8), Research Center Jülich, 52425 Jülich, Germany \\ 3 gerbion $\mathrm{GmbH} \& \mathrm{Co}$ KG, 70806 Kornwestheim, Remsstr. 1, Germany \\ 4 Institute of Pharmaceutical Chemistry, Philipps University Marburg, 35032 Marburg, \\ Marbacher Weg 6-10, Germany \\ * Correspondence: schoening@fh-aachen.de \\ † Presented at the 5th International Symposium on Sensor Science (I3S 2017), Barcelona, Spain, \\ 27-29 September 2017.
}

Published: 24 November 2017

Field-effect EIS (electrolyte-insulator-semiconductor) sensors modified with a positively charged weak polyelectrolyte layer have been applied for the electrical detection of DNA (deoxyribonucleic acid) immobilization and hybridization by the intrinsic molecular charge. The EIS sensors are able to detect the existence of target DNA amplicons in PCR (polymerase chain reaction) samples and thus, can be used as tool for a quick verification of DNA amplification and the successful PCR process. Due to their miniaturized setup, compatibility with advanced micro- and nanotechnologies, and ability to detect biomolecules by their intrinsic molecular charge, those sensors can serve as possible platform for the development of label-free DNA chips. Possible application fields as well as challenges and limitations will be discussed.

(C) 2017 by the authors. Licensee MDPI, Basel, Switzerland. This article is an open access article distributed under the terms and conditions of the Creative Commons Attribution (CC BY) license (http://creativecommons.org/licenses/by/4.0/). 